\title{
Epidemiology of Childhood Malignancies
}

National Cancer Institute

\section{Source}

National Cancer Institute. Epidemiology of Childhood Malignancies. NCI Thesaurus. Code C19551.

A subdiscipline of epidemiology focusing on determination of causes and incidence of malignancies in children. 